\title{
Entrevista com o Dr. Francisco José de Freitas
}

\author{
Francisco de Freitas é Mestre em Neurologia do Centro de Ciências Biológicas e da Saúde da UNIRIO \\ Especialista em Homeopatia realizada no Instituto Hahnemanniano do Brasil \\ e École Française dHoméopathie \\ Possui Aperfeiçoamento no Institut National Homeeopathie Francais \\ É Médico formado pela Universidade Federal do Estado do Rio de Janeiro - UNIRIO \\ Professor adjunto IV, responsável pela disciplina obrigatória Homeopatia e Outras Racionalidades Médicas da \\ Escola de Medicina e Cirurgia - UNIRIO \\ Chefe do Departamento de Homeopatia e Terapêutica Complementar - UNIRIO \\ Coordenador da residência médica em Homeopatia do Hospital Universitário Gaffrée e Guinle - UNIRIO \\ Membro da Câmara Técnica de Homeopatia do Conselho Regional de Medicina do Estado do Rio de Janeiro \\ Membro do Comitê Técnico Temático da Farmacopeia Homeopática Brasileira (ANVISA) \\ Co-autor da Terceira Edição da Farmacopeia Homeopática Brasileira \\ Doutor em Ciências Biológicas (UFRJ), Professor Associado do Departamento de Zoologia (UERJ) \\ $\triangle$ fjdefreitas@gmail.com
}

\section{A Revista SUSTINERE tem a satisfação de entrevistar o Dr. Francisco José de Freitas e a primeira pergunta é:}

Qual a sua Formação Acadêmica e experiência profissional? o que o (a) motivou na escolha da profissão? Como incentivar os alunos a ingressarem na Homeopatia?

Sou médico homeopata desde 1984 e professor efetivo de Homeopatia desde 1987 na Escola de Medicina e Cirurgia da UNIRIO, doutorando do Programa de Enfermagem e Biociências da UNIRIO. Sou filho de médico e desde criança quis ser médico, ingressei na Escola de Medicina e Cirurgia da UNIRIO, onde tive a oportunidade de ter o meu primeiro contato com a homeopatia no meu terceiro ano médico, que corresponde hoje ao $5^{\circ}$ período. Era uma disciplina optativa que entrei por influência dos meus melhores colegas de turma, pois nem sabia o que significava homeopatia. Fiquei fascinado pelos seus conceitos, fundamentos e prática, onde acabei fazendo mais outras duas disciplinas optativas sobre homeopatia. Durante a minha graduação, a Homeopatia foi reconhecida oficialmente como especialidade médica, em 1980, pelo Conselho Federal de Medicina. Percebi, na época, o grande potencial clínico da homeopatia que leva em conta não somente a totalidade sintomática individual do paciente, mas considera também seus aspectos fisiopatológicos, sinais e sintomas físicos e psíquicos, estado emocional e sono, hábitos alimentares e de vida, incluindo suas atividades físicas, social, meio familiar, entre outros. Tudo no sentido de compreender o porquê do seu adoecimento, a fim de realizarmos uma melhor orientação e 
medicação mais adequada a cada caso. Portanto, uma grande contribuição a uma melhor e mais completa formação médica, o que me fez também despertar o meu interesse na questão acadêmica. Apesar da sua oficialidade, naquela época e ainda até hoje, alguns médicos desconhecem as suas comprovações científicas, o que me fez ir para a França em 1983 para aprofundar os conhecimentos dessa especialidade médica, onde fui bolsista do CNPq por dois anos. Tive a oportunidade de aprender homeopatia com grande mestres e pesquisadores no exterior e do Brasil. Logo em seguida me tornei professor de homeopatia na faculdade em que cursei e leciono até hoje.

Quanto ao incentivo aos alunos em ingressar na homeopatia, não é tarefa das mais simples. Além da realidade da diminuição do interesse dos novos formandos nas especialidades clínicas gerais, como clínica médica, pediatria entre outras, nas quais se incluem a homeopatia, nos últimos anos, são muito poucas as faculdades de medicina que oferecem algum ensino dessa especialidade na sua graduação, dificultando o seu conhecimento. Só para vocês terem um quadro real, esse ano a Homeopatia está fazendo 40 anos como especialidade médica reconhecida no Brasil e a EMC da UNIRIO é a única no país que tem uma disciplina obrigatória no seu ensino curricular de graduação e muito poucas a ensinam como optativa, extensão ou mesmo pós-graduação lato-senso. Somente quatro serviços no país possuem Residência Médica em Homeopatia: nós no Hospital Universitário Gaffrée e Guinle da UNIRIO há 16 anos, mais recentemente em Betim - MG e Campo Grande MS e esse ano está sendo implementada em Vitória - ES. Esses fatos complicam muito o acesso do conhecimento da homeopatia na formação médica, momento fundamental na construção crítica de qualquer profissional. Nesses anos de professor tanto de graduação quanto de especialização, junto aos depoimentos dos próprios alunos, a forma mais eficaz de incentivo a ingressarem na Homeopatia, é estar em contato com a prática clínica homeopática, local onde eles podem acompanhar e participar das consultas e comprovarem os seus resultados. Para sermos bons médicos necessitamos ter conhecimento e prática a fim de adquirirmos competências e habilidades fundamentais na prática clínica e compreensão dos nossos pacientes.

Diante da sua escolha pela Homeopatia como especialidade da Medicina qual a importância do tema para a Sociedade?

Quem se trata com a Homeopatia conhece a sua ação tanto curativa quanto preventiva e, consequentemente, acaba levando toda a sua família diante da abordagem holística descrita 
acima, ou seja, o médico homeopata acaba se tornando o médico da família, aconselhando, orientando e medicando a todos. A prática médica homeopática leva o paciente a se observar melhor, reconhecer seus hábitos de vida que podem estar ajudando ou prejudicando a sua saúde, otimiza a relação médico-paciente e adesão ao tratamento e consequente melhor cuidado consigo mesmo. Este movimento de conscientização do paciente junto ao tratamento medicamentoso homeopático contribui a promoção da sua própria saúde, e aquisição de hábitos de vida mais saudáveis. Esse conjunto de medidas ajuda o organismo a responder de maneira mais eficaz a alguma doença que queira se instalar ou já estabelecida, tanto nos doentes crônicos quanto agudos.

Como se desenvolveu o tema no passado e presente? Quais as perspectivas futuras?

A homeopatia ao longo das últimas décadas vem comprovando cientificamente a sua eficácia, o que melhorou bastante o preconceito existente no passado, o qual convivi nos meus mais de 30 anos de meio científico e acadêmico. Mas apesar da homeopatia ser melhor conhecida atualmente pela sociedade em geral e acadêmica, muitos profissionais da saúde, por não terem tido a oportunidade de estudarem nas suas graduações, ainda podem ter uma visão não real da sua capacidade terapêutica. O Brasil é um dos países que mais cresceu na produção científica homeopática que comprovam a sua eficácia e tenho constatado o crescente reconhecimento da sociedade médica, científica e geral.

Qual a visão homeopática de desafios como esta pandemia? Como pode a Homeopatia ajudar neste momento onde não só a saúde física, mas a mental se acham tão comprometidas?

As gripes, rinofaringites, viroses e os distúrbios de ansiedade leves, dentre outras patologias, são comumente tratadas pela homeopatia, sendo frequente a sua indicação por profissionais da saúde bem como a procura espontânea pelos pacientes por esta forma de tratamento. Além de aliviar os sintomas, o tratamento homeopático também demonstra contribuir para deixar o organismo menos vulnerável diante de agravos à saúde tanto física quanto psíquica. A Homeopatia tem sido anteriormente empregada em epidemias, com resultados promissores em algumas destas, sendo sua segurança comprovada por estudos científicos. 
Neste momento de pandemia deflagrada pelo novo coronavírus SARS-CoV2 e a doença causada por ele, a terapêutica homeopática tem a possibilidade de oferecer a sua contribuição como coadjuvante a todas medidas sanitárias e terapêuticas preconizadas pelas autoridades da saúde.

A atuação da homeopatia nesta epidemia já vem ocorrendo de formas isoladas, seja por meio de secretarias municipais e/ou pela orientação direta dos médicos homeopatas aos seus pacientes. A AMHB (Associação Médica Homeopática Brasileira) criou a "Plataforma Homeopatia na COVID-19", onde convoca todos os médicos homeopatas para contribuírem no atendimento e registro de pacientes com COVID, com a participação e troca de experiências entre os médicos homeopatas. Essa iniciativa com o apoio dos conselhos regionais e federal de medicina, além do respaldo da ABFH (Associação Brasileira de Farmacêuticos Homeopatas) que vão oferecer o medicamento homeopático a preço bem reduzido, para que a população tenha um melhor acesso à medicação. Os resultados do tratamento homeopático, dessa forma, estão sendo catalogados para demonstrar a real contribuição coadjuvante ao combate da COVID-19, que preliminarmente tem demonstrado a sua ação tanto nos casos mais leves quanto nos mais severos ajudando a esses pacientes terem evolução mais favorável.

Em seu ponto de vista quais são os desafios enfrentados pelos profissionais da Homeopatia dentro do mercado de trabalho? Como está no momento, a valorização do profissional, há um plano de carreira ou similar? Haveria algum conselho ou sugestão para aqueles que ingressam na profissão, especificamente nesta especialização?

Os desafios enfrentados pelo profissionais da área da saúde e especificamente os médicos, qualquer que seja a sua especialidade, ficam mais evidentes e agudizados em momentos de crises na saúde, como a que estamos vivendo atualmente. Infelizmente não há uma real valorização dos profissionais da área da saúde pelos nossos dirigentes, nem plano de carreira, como verificamos em outras profissões, como no judiciário e militares. É muito clara, principalmente neste momento de epidemia, a fragilidade dos nossos sistemas de saúde tanto público quanto particular.

Para os médicos homeopatas, o panorama não é diferente. Conseguirmos implementar uma ação de qualquer natureza, seja assistencial ou de pesquisa, esbarramos na burocracia habitual e morosidade da máquina administrativa, agravada pelo desconhecimento por parte 
dos gestores dos reais benefícios da terapêutica homeopática. Apesar de termos uma Política Nacional de Práticas Integrativas e Complementares no SUS - PNPICS aprovada desde 1986 e reeditada em 2015 pelo Ministério da Saúde, com a finalidade de implantar e implementar a homeopatia, entre outras, no SUS, ainda são muito poucos os serviços que a ofertam à população a fim de se tratarem com médicos homeopatas na nossa cidade, estado e país. Porém, de forma muito tímida alguns municípios tem oferecido concursos para médicos homeopatas para o SUS. Na clínica privada e nos planos de saúde, a homeopatia já encontrase implementada como as outras especialidades médicas já à décadas.

Agradecemos a sua participação e gostaríamos de solicitar que deixe um breve recado ou complemente as respostas anteriores

Quando me formei, no início dos anos 80, a Homeopatia era quase exclusivamente praticada em consultórios e ambulatórios. Os questionamentos sobre a sua eficácia ainda eram bem grandes. Nestes últimos 40 anos, não somente os trabalhos científicos comprobatórios da sua ação se multiplicaram, se estabelecendo de forma paulatina, mas consistente, nos meios acadêmicos como também vem sendo utilizada de forma crescente na saúde pública, inclusive em pacientes internados. Já comprovou historicamente e mais recentemente a sua contribuição em epidemias. Com a atual pandemia, algumas secretarias municipais de saúde nos estados do Rio de Janeiro, São Paulo, Minas Gerais, Santa Catarina e Mato Grosso do Sul estão utilizando a terapêutica homeopática como tratamento coadjuvante por meio de trabalhos científicos. Apesar de todas dificuldades inerentes de uma jovem especialidade terapêutica, a Homeopatia tem se firmado nos meios de saúde, tem o seu reconhecimento oficial reconhecido pelos órgãos públicos, justamente devido a essas comprovações, demonstrando ser uma grande e segura contribuição à saúde de todos, concretizando o seu presente e futuro promissor.

\section{(cc) $\mathrm{EY}$}

Este trabalho está licenciado com uma Licença Creative Commons - Atribuição 4.0 Internacional. 